\title{
Caracterização hidrológica das bacias hidrográficas dos rios Peruípe, Itanhém e Jucuruçu
}

Hydrological characterization of the Peruípe, Itanhém and Jucuruçu watershed

\author{
E. S. Farias ${ }^{1 *}$; G. M. F. Silva ${ }^{2}$; J. B. L da Silva ${ }^{1}$; D. P. da Silva ${ }^{3}$; L. C. Pires ${ }^{1}$ \\ ${ }^{1}$ Programa de Pós Graduação em Ciências e Tecnologias Ambientais, Universidade Federal do Sul da Bahia, 45810- \\ 000, Porto Seguro - BA, Brasil \\ ${ }^{2}$ Instituto Federal da Bahia, 45078-300, Vitória da Conquista - BA, Brasil \\ ${ }^{3}$ Universidade Estadual do Sudoeste da Bahia, 45700-000, Itapetinga-BA, Brasil \\ *emillyfarias10@hotmail.com
}

(Recebido em 07 de abril de 2020, aceito em 17 de agosto de 2020)

\begin{abstract}
A caracterização hidrológica de uma bacia hidrográfica é de grande eficácia para otimização de seu uso, pois permite que ocorram planejamentos e gerenciamentos adequados para o uso de seus recursos hídricos. Portanto, esse trabalho teve como objetivo caracterizar o comportamento hidrológico e verificar a produtividade hídrica das bacias hidrográficas dos rios Peruípe, Itanhém e Jucuruçu. Para tanto, fez-se a análise de séries históricas de 22 estações pluviométricas, obtendo precipitação média anual e total precipitado no trimestre mais seco e mais chuvoso; e 8 estações fluviométricas, que a partir dos dados históricos de cotas fez-se o ajuste de curvas-chave, para estimar novas vazões em função da cota medida. Obteve-se, a partir das vazões reestimadas, as variáveis: Qmed, $\mathrm{Qmax}, \mathrm{Q}_{7}, \mathrm{Q}_{50}, \mathrm{Q}_{90} \mathrm{e} \mathrm{Q}_{95}$, bem como as vazões específicas de cada estação. Realizou-se ainda a análise da estacionariedade das vazões e da precipitação anual. Os resultados apontam que as estações que se localizam mais a oeste apresentaram períodos secos e chuvosos mais acentuados, enquanto nas estações mais próximas ao litoral tais períodos foram menos marcados. Uma vez que as vazões específicas representam a produtividade hídrica por área de drenagem, pode-se afirmar que a bacia do rio Jucuruçu apresentou a maior produtividade hídrica. Em relação a disponibilidade hídrica ao longo do tempo, as estações fluviométricas apresentaram tendência de diminuição de suas vazões, principalmente em relação as vazões mínimas. Tais fatos demonstram a necessidade de manejo adequado dessas bacias a fim de evitar a instalação de uma crise hídrica na região.

Palavras-chave: hidrologia, precipitação, vazão.
\end{abstract}

The hydrological characterization of a hydrographic basin is of great efficiency to optimize its use, as it allows adequate planning and management to occur for the use of its water resources. Therefore, this work aimed to characterize the hydrological behavior and to verify the water productivity of the hydrographic basins of the Peruípe, Itanhém and Jucuruçu rivers. For that, the analysis of historical series of 22 pluviometric stations was made, obtaining average annual precipitation and total precipitate in the driest and rainiest quarter; and 8 fluviometric stations, which, based on historical quota data, made the adjustment of key curves to estimate new flow rates as a function of the measured quota. From the re-estimated flows, the variables Qmed, Qmax, Q7, Q50, Q90 and Q95 were obtained, as well as the specific flows for each season. Flow stationarity and annual precipitation were also analyzed. The results show that the stations that are located more to the west presented more pronounced dry and rainy periods, while in the stations closer to the coast, such periods were less marked. Since the specific flows represent water productivity by drainage area, it can be said that the Jucuruçu river basin had the highest water productivity. In relation to water availability over time, fluviometric stations showed a tendency to decrease their flows, mainly in relation to minimum flows. Such facts demonstrate the need for proper management of these basins in order to avoid the installation of a water crisis in the region.

Keywords: hydrology, precipitation, flow rate.

\section{INTRODUÇÃO}

As bacias hidrográficas dos rios Peruípe, Itanhém e Jucuruçu estão localizadas no território de identidade do extremo sul da Bahia e abrangem parcial ou completamente 15 municípios baianos e 9 municípios mineiros, ocupando uma área de aproximadamente $16 \mathrm{mil} \mathrm{km}^{2}$. Desde que foi descoberta, essa região vem sendo ocupada de forma efetiva e a exploração da Mata Atlântica com a extração de madeira foi intensa, ocorrendo as primeiras mudanças no início do século XIX, com 
a introdução das culturas do café e do cacau. Até meados do século XX, a região permaneceu praticamente isolada do resto do estado, com atividades agrícolas escassas $[1,2]$.

Entre as décadas de 1960 e 1970 diversas medidas governamentais foram efetivadas, com o objetivo de favorecer o desenvolvimento de empreendimentos florestais através da Lei de Incentivos Fiscais para Empreendimentos Florestais, o II Plano Nacional de Desenvolvimento e I Programa Nacional de Papel e Celulose. Com tais medidas e com a construção do trecho Vitória Salvador, da Rodovia Governador Mário Covas (BR 101), no ano de 1970, as características agrícolas e econômicas locais começaram a mudar, devido a instalação de um número significativo de madeireiras e serrarias, bem como a expansão da pecuária, que se caracterizava como principal atividade econômica desse período $[1,3,4,5]$.

A expansão das atividades agroindustriais e florestais propiciou a inserção dessa região não só no cenário econômico nacional, como também internacional, gerando modernização, industrialização e crescimento populacional $[2,6,7,8]$, porém, tal fato tem como uma de suas consequências a grande demanda pelos recursos hídricos. Para tanto, foi instituída em 1997 a Política Nacional dos Recursos Hídricos (PNRH) sob a Lei n. 9.433, que visa consolidar a gestão dos recursos hídricos no Brasil. É objetivo dessa lei assegurar à geração atual e às gerações futuras a disponibilidade de água em padrões de qualidade adequados [9]. Além da PNRH, em 2009 foi instituído o comitê das bacias hidrográficas dos rios Peruípe, Itanhém e Jucuruçu através do Conselho Estadual de Recursos Hídricos (CONERH) pela resolução n. 63/2009 [10], que tem por finalidade assegurar o acesso da água das bacias a todos indivíduos, evitando conflitos de uso.

Apesar da implementação da Lei n. 9.433/1997 significar um importante avanço na gestão dos recursos hídricos do país, ainda existem pontos que devem ser melhorados, principalmente no que diz respeito aos fatores requeridos no processo de outorga, considerado como essencial para evitar conflitos de uso da água $[11,12]$. Um dos pontos de fundamental importância para a eficácia desse processo é o conhecimento da produtividade hídrica em diferentes pontos da bacia hidrográfica pois, com base nesses dados, é possível gerir os recursos hídricos de modo a atender as necessidades ambientais e antrópicas [13].

A produtividade ou disponibilidade hídrica passa por variações no tempo e no espaço, e podem ser alteradas tanto por fatores naturais, quanto por fatores antrópicos, tornando a relação entre chuva-vazão complexa e dependente da análise de diferentes atributos das bacias [14, 15]. Tais variáveis podem ser estimadas através da caracterização hidrológica da bacia hidrográfica, a partir de séries históricas de dados fluviométricos e pluviométricos [16, 17]. Os valores de referência mais utilizados para a indicação da disponibilidade de água são a $\mathrm{Q}_{7}$, a $\mathrm{Q}_{90}$ e a $\mathrm{Q}_{95}$, sendo esses indicadores associados ao tempo em que a vazão é igualada ou superada em um período prédeterminado [18].

Portanto, a caracterização hidrológica de uma bacia hidrográfica é de grande eficácia para o uso otimizado de suas águas, podendo contribuir para a determinação das disponibilidades hídricas atuais e futuras, além de permitir que sejam identificados locais em déficit hídrico ou suscetíveis a enchentes, permitindo que ocorram planejamentos e gerenciamentos adequados para o uso das águas, de modo a diminuir os problemas ambientais causados pelo uso indiscriminado dos recursos hídricos [19]. Diante disso, esse estudo tem como objetivo caracterizar o comportamento hidrológico e verificar a produtividade e a disponibilidade hídrica das bacias hidrográficas dos rios Peruípe, Itanhém e Jucuruçu, com o intuito de auxiliar o comitê de bacias hidrográficas no planejamento e gestão dos recursos hídricos locais.

\section{MATERIAL E MÉTODOS}

\section{1 ÁREA DE ESTUDO}

A área do estudo corresponde às bacias hidrográficas dos rios Itanhém - $7794\left(6.360,07 \mathrm{~km}^{2}\right)$, Peruípe - $77952\left(4.667,27 \mathrm{~km}^{2}\right)$ e Jucuruçu - $7792\left(5.954,81 \mathrm{~km}^{2}\right)$. Essas bacias são gerenciadas pelo Comitê de Bacias Hidrográficas dos rios Peruípe, Itanhém e Jucuruçu (CBHPIJ), que faz parte da Região de Planejamento e Gestão das Águas III (RPGA III) do estado da Bahia.

A bacia hidrográfica do rio Peruípe é formada pelos municípios de Caravelas, Ibirapuã, Lajedão, Nova Viçosa e Teixeira de Freitas, todos localizados no extremo sul da Bahia, sendo limitada pelas 
bacias dos rios Itanhém (ao norte) e Mucuri (ao sul e a oeste), e pelo Oceano Atlântico ao leste. A bacia do rio Itanhém localizada nas regiões Sudeste e Nordeste, nos estados de Minas Gerais (Bertópolis, Umburatiba, Machacalis e Santa Helena de Minas) e na Bahia (Alcobaça, Itanhém, Medeiros Neto e Teixeira de Freitas), sendo limitada pelas bacias dos rios Jequitinhonha e Jucuruçu (ao norte), a oeste a ao sul pelos rios Mucuri e Peruípe, e pelo Oceano Atlântico, ao leste, tem como principal afluente o rio Itanhetinga, que fica na margem esquerda. Assim como a bacia do rio Itanhém, a bacia do Jucuruçu se localiza nos estados de Minas Gerais (Felisburgo, Palmópolis e Rio do Prado) e Bahia (Itamaraju, Jucuruçu, Prado e Vereda), sendo limitada pelas bacias do rio Jequitinhonha (a oeste), do rio Itanhém (ao sul), dos rios Caraíva e Buranhém (ao norte), e pelo Oceano Atlântico (ao leste) (Figura 1) [20].
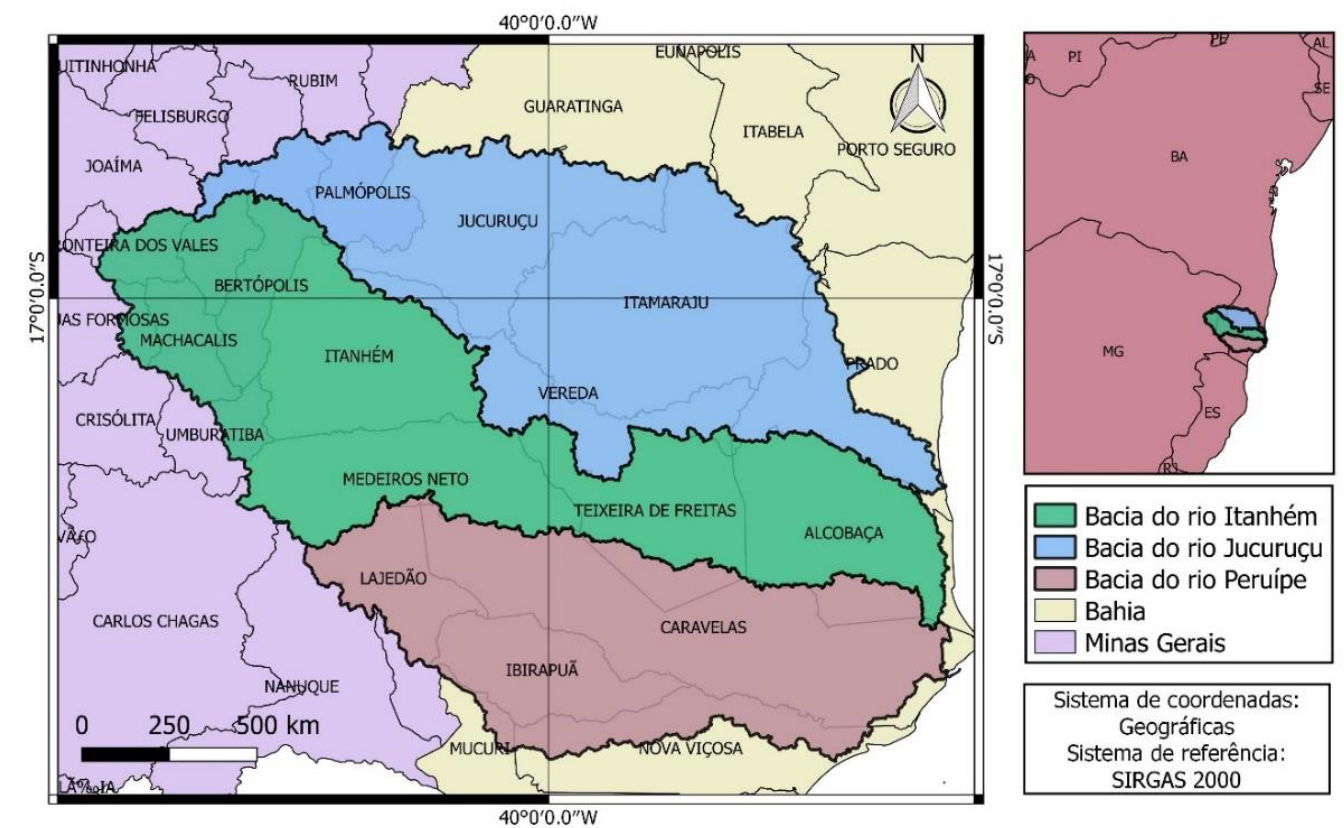

Figura 1: Área de abrangência das bacias hidrográficas dos rios Peruípe, Itanhém e Jucuruçu, Bahia. Fonte: os autores

A região onde as bacias estudadas estão localizadas, possui clima tropical úmido no litoral e tropical subúmido no interior, com cobertura vegetal de floresta ombrófila densa, sob o domínio de Mata Atlântica. As chuvas são bem distribuídas ao longo do ano, com período mais intenso de chuvas entre os meses de novembro a janeiro e não há índices pluviométricos mensais inferiores a $60 \mathrm{~mm}$. A pluviosidade média anual está em torno de $1.100 \mathrm{~m}$, com temperaturas entre $23^{\circ} \mathrm{C} \mathrm{e} 27^{\circ} \mathrm{C}$. A bacia do rio Peruípe é predominada por relevo Plano (46,3\%), enquanto na bacia do rio Itanhém predomina-se o relevo Ondulado $(29,3 \%)$ e na bacia do rio Jucuruçu, o relevo Forte Ondulado $(38,5 \%)$, de acordo com as classes determinadas pela EMBRAPA [1, 21].

\subsection{OBTENÇÃO DAS SÉRIES HISTÓRICAS}

A análise hidrológica contou com informações de séries histórias de estações pluviométricas e fluviométricas, importadas do sítio eletrônico da Agência Nacional de Águas [22]. As estações estão distribuídas nos municípios que fazem parte e que cercam as bacias dos rios Itanhém, Peruípe e Jucuruçu, pertencentes aos estados da Bahia, Minas Gerais e Espírito Santo. Foram analisadas 8 estações fluviométricas (Tabela 1) e 22 de 57 estações pluviométricas, tendo sido analisadas apenas as que estão dentro das bacias e na área de influência, que compreende até $30 \mathrm{~km}$ de distância dos divisores de águas das bacias, que possuíam série de dados atuais e com mais de 20 anos (Tabela 2). 
Tabela 1: Estações fluviométricas pertencentes as bacias dos rios Peruípe, Itanhém e Jucuruçu, Bahia.

\begin{tabular}{lllcccc}
\hline Código & Nome da estação & Município & $\begin{array}{c}\text { Bacia } \\
\text { Hidrográfica }\end{array}$ & Latitude & Longitude & $\begin{array}{c}\text { Área de } \\
\text { Drenagem } \\
\left(\mathbf{k m}^{2} \mathbf{)}\right.\end{array}$ \\
\hline 55340000 & Itamaraju & Itamaraju & Jucuruçu & $-17,0453$ & $-39,5436$ & 2760,00 \\
55360000 & São José do Prado & Nazaré & Jucuruçu & $-17,1875$ & $-39,9822$ & 878,00 \\
55370000 & Cachoeira Grande & Prado & Jucuruçu & $-17,2528$ & $-39,7742$ & 1800,00 \\
55380000 & Fazenda Rio do Sul & Prado & Jucuruçu & $-17,2494$ & $-39,6211$ & 1980,00 \\
55460000 & Medeiros Neto & Medeiros Neto & Itanhém & $-17,3753$ & $-40,2214$ & 3230,00 \\
55490000 & Fazenda Cascata & Teixeira de Freitas & Itanhém & $-17,5128$ & $-39,6450$ & 4720,00 \\
55510000 & Helvécia & Nova Viçosa & Peruípe & $-17,7992$ & $-39,6639$ & 2960,00 \\
55330000 & Jucuruçu & Jucuruçu & Jucuruçu & $-16,8381$ & $-40,1572$ & 936,00 \\
\hline
\end{tabular}

Fonte: ANA (2020) [22].

Tabela 2: Estações pluviométricas pertencentes à área de influência das bacias dos rios Peruípe, Itanhém e Jucuruçu, Bahia.

\begin{tabular}{llccccc}
\hline Código & Nome & Início da série & Fim da série & Duração (anos) & Latitude & Longitude \\
\hline 01640000 & Jacinto & jan/48 & jun/19 & 71 & $-16,1386$ & $-40,2903$ \\
01640009 & Rubim & abr/95 & jun/19 & 24 & $-16,3789$ & $-40,5408$ \\
01640010 & Felisburgo & abr/95 & jun/19 & 24 & $-16,6342$ & $-40,7606$ \\
01640012 & Jucuruçu & dez/92 & jun/19 & 27 & $-16,8386$ & $-40,1564$ \\
01641002 & Jequitinhonha & mar/41 & jun/19 & 78 & $-16,4275$ & $-41,0139$ \\
01739001 & Prado & jun/54 & jun/19 & 65 & $-17,3503$ & $-39,2200$ \\
01739005 & Itamaraju & jun/54 & jun/19 & 65 & $-17,0450$ & $-39,5447$ \\
01739006 & Helvécia & dez/41 & jun/19 & 78 & $-17,8081$ & $-39,6625$ \\
01739010 & Alcobaça & ago/53 & jun/19 & 66 & $-17,5156$ & $-39,2275$ \\
01739020 & Fazenda Cascata & dez/92 & jun/19 & 27 & $-17,5103$ & $-39,6411$ \\
01739021 & Cachoeira Grande & jan/93 & jan/19 & 26 & $-17,2536$ & $-39,7783$ \\
01739022 & Fazenda Rio do Sul & dez/92 & jun/19 & 27 & $-17,2494$ & $-39,6222$ \\
01740000 & Carlos Chagas & mai/45 & jun/19 & 74 & $-17,7056$ & $-40,7597$ \\
01740001 & Nanuque & nov/42 & jun/19 & 77 & $-17,8375$ & $-40,3772$ \\
01740005 & Medeiros Neto & nov/52 & jun/19 & 67 & $-17,3722$ & $-40,2258$ \\
01740006 & São José do Prado & ago/54 & jun/19 & 65 & $-17,1875$ & $-39,9822$ \\
01740008 & Itanhém & out/65 & jun/19 & 54 & $-17,1633$ & $-40,3267$ \\
01740026 & São Pedro do Pampa & jan/77 & jun/19 & 42 & $-17,3203$ & $-40,6761$ \\
01740033 & Águas Formosas & abr/95 & jun/19 & 24 & $-17,0825$ & $-40,9408$ \\
01839000 & Morro d'Anta & jan/51 & jun/19 & 68 & $-18,2994$ & $-39,9586$ \\
01839001 & Conceição da Barra & jul/30 & jun/19 & 89 & $-18,5622$ & $-39,7472$ \\
01840012 & Fazenda Limoeiro & jan/70 & mai/19 & 49 & $-18,1456$ & $-40,1439$ \\
\hline
\end{tabular}

Fonte: ANA (2020) [22].

\subsection{CORREÇÃO DOS DADOS FLUVIOMÉTRICOS}

Foram importados do sítio eletrônico da Agência Nacional de Águas [22], os dados históricos referentes ao resumo de descarga das estações fluviométricas. No resumo de descarga se encontra disponível, dentre outras informações da seção do curso d'água monitorado, série histórica de dados de cotas e vazão aferidos em campo, com os quais fez-se o ajuste de curvas-chave para cada estação. Por meio das curvas-chave e respectivas séries históricas diárias de cotas [22] das estações fluviométricas, foram obtidas as séries de vazões. 
Essa etapa foi realizada com auxílio de planilhas eletrônicas de dados, onde realizou-se a plotagem de gráficos de dispersão e a inserção de linhas de tendência para gerar uma equação de regressão, sendo escolhidas as curvas que melhor se ajustaram. Quando necessário, houve a divisão da série de dados em diferentes períodos para que houvesse um melhor ajuste da equação.

Tabela 3: Curvas-chave ajustadas para as estações fluviométricas pertencentes as bacias dos rios Peruípe, Itanhém e Jucuruçu, Bahia, o período a que dizem respeito e o coeficiente de determinação $\left(R^{2}\right)$.

\begin{tabular}{cccc}
\hline Estação & Curva Chave & Período & $\mathbf{R}^{2}$ \\
\hline 55330000 & $\mathrm{Y}=0,0003 \mathrm{x}^{2}+0,0391 \mathrm{x}$ & 1981 a 2015 & 0,9106 \\
\hline & $\mathrm{Y}=2\left(10^{-8}\right) \mathrm{x}^{4}-9\left(10^{-6}\right) \mathrm{x}^{3}+0,0013 \mathrm{x}^{2}+0,1348 \mathrm{x}$ & 1954 a 1989 & 0,9455 \\
55340000 & $\mathrm{Y}=2\left(10^{-6}\right) \mathrm{x}^{3}-0,0006 \mathrm{x}^{2}+0,1982 \mathrm{x}$ & 1991 a 1999 & 0,9872 \\
& $\mathrm{Y}=0,195 \mathrm{x}$ & 2000 a 2008 & 0,9078 \\
& $\mathrm{Y}=0,0003 \mathrm{x}^{2}+0,0715 \mathrm{x}$ & 2009 a 2015 & 0,985 \\
\hline 55360000 & $\mathrm{Y}=4\left(10^{-8}\right) \mathrm{x}^{3,6363}$ & 1954 a 2015 & 0,8822 \\
\hline 55370000 & $\mathrm{Y}=0,0004 \mathrm{x}^{2}-0,0701 \mathrm{x}$ & 1965 a 2015 & 0,9888 \\
\hline 55380000 & $\mathrm{Y}=6\left(10^{-7}\right) \mathrm{x}^{3}+1\left(10^{-4}\right) \mathrm{x}^{2}+0,129 \mathrm{x}$ & 1968 a 2015 & 0,9877 \\
\hline \multirow{2}{*}{55460000} & $\mathrm{Y}=0,0012 \mathrm{x}^{2}-0,1197 \mathrm{x}$ & 1952 a 1969 & 0,9838 \\
& $\mathrm{Y}=0,0029 \mathrm{x}^{2}-0,3926 \mathrm{x}$ & 1969 a 2015 & 0,9137 \\
\hline 55490000 & $\mathrm{Y}=2\left(10^{-8}\right) \mathrm{x}^{4}-9\left(10^{-6}\right) \mathrm{x}^{3}+0,0021 \mathrm{x}^{2}-0,0263 \mathrm{x}$ & 1978 a 2015 & 0,9361 \\
\hline & $\mathrm{Y}=0,0524 \mathrm{x}$ & 1962 a 1966 & 0,9824 \\
55510000 & $\mathrm{Y}=1\left(10^{-5}\right) \mathrm{x}^{3}-0,003 \mathrm{x}^{2}+0,3494 \mathrm{x}$ & 1969 a 1973 & 0,8646 \\
& $\mathrm{Y}=8\left(10^{-6}\right) \mathrm{x}^{3}-0,002 \mathrm{x}^{2}+0,3224 \mathrm{x}$ & 1974 a 1987 & 0,9325 \\
& $\mathrm{Y}=0,0004 \mathrm{x}^{2}+0,0505 \mathrm{x}$ & 1988 a 1989 & 0,9499 \\
& $\mathrm{Y}=2\left(10^{-6}\right) \mathrm{x}^{3}-0,0004 \mathrm{x}^{2}+0,1037 \mathrm{x}$ & 1992 a 2015 & 0,9865 \\
\hline
\end{tabular}

Fonte: os autores.

\subsection{TRATAMENTO DAS VARIÁVEIS HIDROLÓGICAS}

As séries de vazões foram submetidas ao Sistema Computacional para Análises Hidrológicas SisCAH 1.0 [23]. A princípio identificou-se o início do ano hidrológico, através da análise da ascensão do histograma das vazões médias mensais, sendo definido o mês de outubro como o início do período chuvoso em todas as estações. O pré-processamento dos dados consistiu, portanto, na definição do início do ano hidrológico e na seleção do descarte de dados com falha superior a $30 \%$ mensais. Em seguida, foram obtidas as vazões: média, máxima, mínima com duração de 7 dias $\left(\mathrm{Q}_{7}\right)$, e as vazões associadas às curvas de permanência de $50 \%\left(\mathrm{Q}_{50}\right), 90 \%\left(\mathrm{Q}_{90}\right)$ e $95 \%\left(\mathrm{Q}_{95}\right)$ ao ano. As vazões médias específicas, utilizadas para determinar a disponibilidade hídrica, como também a produtividade hídrica, por trecho da bacia, ou seja, no espaço ou localidade, foram obtidas através da divisão de cada vazão calculada pelas áreas de drenagem a montante da estação fluviométrica.

Assim como as séries de vazões, as séries de precipitações passaram por pré-processamento com a exclusão de anos com mais de $30 \%$ de falhas e em seguida foram submetidas ao software Hidro 1.4 [24] para cálculo dos totais mensais precipitados. Com apoio de planilhas eletrônicas, calculouse: precipitação média anual em toda a série, sendo considerado o ano hidrológico com início em outubro de um ano e final em setembro do ano seguinte; e o total precipitado no trimestre mais seco e o trimestre mais chuvoso da série, através das médias mensais de cada estação.

Para calcular a precipitação anual média na área de drenagem de cada bacia utilizou-se o método dos polígonos de Thiessen. Nessa etapa, utilizou-se o software de informações geográficas QGIS 3.4® [25] para delimitação das áreas de influência de cada estação pluviométrica. Em seguida, foi determinado um coeficiente para cada uma das estações, que serviram de parâmetro para calcular a contribuição média de cada uma delas. 


\subsection{ANÁLISE DA ESTACIONARIEDADE DA SÉRIE DE DADOS}

Tanto para as séries de vazão quanto para as séries de precipitação, foram realizados os testes estatísticos de Student (T) e Fisher (F) para verificação das hipóteses (H0) de igualdade das médias e das variâncias $(p<0,05)$. Deste modo, analisou-se a estacionariedade das vazões médias, mínimas e máximas anuais e da precipitação anual em cada estação, de modo a verificar a disponibilidade hídrica das estações fluviométricas ao longo do tempo.

\subsection{ANÁLISE DOS LIMITES OUTORGÁVEIS}

O cálculo das vazões passíveis de outorga para as estações pertencentes as bacias, foi realizado com base nas disposições do Decreto n. 6.296 de 21 de março de 1997 [26] para o rio estadual (Peruípe) e da Lei n. 9.433 de 8 de janeiro de 1997 [9] para os rios federais (Itanhém e Jucuruçu). Foram utilizados os relatórios disponíveis no sítio eletrônico da Agência Nacional de Águas (ANA), e o módulo de monitoramento do Sistema Estadual de Informações Ambientais e Recursos Hídricos (SEIA), para definição das principais atividades outorgadas atualmente nas bacias.

\section{RESULTADOS E DISCUSSÃO}

\subsection{ANÁLISE DOS DADOS PLUVIOMÉTRICOS}

A precipitação anual média das 22 estações analisadas é de 1.032,66 mm, com uma variação de $775,22 \mathrm{~mm}$ em Jacinto, localizada no interior do estado, a 1.381,98 $\mathrm{mm}$ em Alcobaça, localizada no litoral (Tabela 4). A Bahia é caracterizada pela alta variabilidade pluviométrica ocasionada pela atuação de diversos sistemas meteorológicos na região, como: Zona de Convergência Intertropical (ZCIT), Vórtices Ciclônicos (VCAN), Sistemas Frontais (FPA) e Zona de Convergência do Atlântico Sul (ZCAS) [27, 28, 29]. 
Tabela 4: Precipitação média anual, desvio padrão (anual) e precipitação média do trimestre mais seco e do trimestre mais chuvoso, em mm, ocorridas na área de abrangência das bacias hidrográficas dos rios Peruipe, Itanhém e Jucuruçu, Bahia.

\begin{tabular}{ccccc}
\hline Estação & Média da Série & DV & Trimestre Seco & Trimestre Chuvoso \\
\hline 01640000 & 775,22 & 293,11 & 68,90 & 360,50 \\
01640009 & 796,56 & 269,63 & 47,00 & 341,50 \\
01640010 & 876,32 & 214,19 & 57,90 & 376,60 \\
01640012 & 1009,18 & 265,78 & 126,9 & 390,60 \\
01641002 & 820,87 & 300,72 & 55,00 & 400,20 \\
01739001 & 1148,92 & 447,98 & 264,80 & 400,80 \\
01739005 & 1257,96 & 379,29 & 249,50 & 435,20 \\
01739006 & 1324,13 & 299,49 & 235,10 & 474,70 \\
01739010 & 1381,98 & 506,17 & 299,70 & 486,20 \\
01739020 & 1063,26 & 385,06 & 201,30 & 419,50 \\
01739021 & 1077,29 & 368,72 & 180,20 & 462,80 \\
01739022 & 1018,32 & 342,45 & 201,00 & 381,20 \\
01740000 & 969,62 & 276,15 & 82,50 & 436,00 \\
01740001 & 890,89 & 302,92 & 99,30 & 390,10 \\
01740005 & 920,18 & 284,26 & 124,20 & 375,80 \\
01740006 & 1024,28 & 362,34 & 162,80 & 391,80 \\
01740008 & 1094,57 & 246,04 & 156,60 & 444,20 \\
01740026 & 940,20 & 306,13 & 96,30 & 411,50 \\
01740033 & 1108,65 & 248,24 & 98,70 & 479,30 \\
01839000 & 959,57 & 419,43 & 159,50 & 421,40 \\
01839001 & 1246,74 & 371,16 & 219,90 & 482,40 \\
01840012 & 1013,71 & 333,11 & 135,90 & 423,50 \\
\hline
\end{tabular}

DV: Desvio Padrão. Fonte: elaborada pelos autores.

Molion e Bernardo (2002) [27] em estudo sobre a climatologia das chuvas do nordeste, identificaram três regimes básicos quanto a distribuição espacial das chuvas, sendo eles: norte do nordeste (NNE), sul do nordeste (SNE) e faixa costeira do nordeste (FCNE), estando as bacias hidrográficas dos rios Peruípe, Itanhém e Jucuruçu localizadas nas duas últimas. De acordo com os autores, os índices pluviométricos entre as regiões SNE e FCNE variam de $600 \mathrm{~mm}$ a mais de 3.000 $\mathrm{mm}$ anuais, sendo encontrados no interior e no litoral, respectivamente. De acordo com Dourado et al. (2013) [29] a distribuição de chuvas no estado da Bahia ocorre de modo que as maiores alturas precipitadas estão concentradas na planície litorânea, enquanto os menores valores se concentram no interior do estado. Ainda de acordo com os autores, esse fato confirma a ação periférica dos sistemas meteorológicos.

O trimestre mais seco nessas estações ocorre entre os meses de julho a agosto, correspondendo em média a $14 \%$ do total anual precipitado, com variação entre 6\% (Rubim) e 23\% (Prado). Nas estações localizadas mais a oeste foram encontrados períodos secos e chuvosos mais acentuados, em contrapartida, nas estações mais próximas ao litoral os totais precipitados nesses períodos foram similares. Os municípios da costa litorânea da Bahia são caracterizados por maior lâmina precipitada e relativa regularidade pluvial durante todo o ano, apresentando menor coeficiente de variação (15\%) entre as diferentes zonas de precipitação no estudo desenvolvido por Dourado et al. (2013) [29], tendo sido descrita como a região de maior altura e regularidade pluviométrica durante toda a série histórica estudada. 


\subsection{POLÍGONOS DE THIESSEN}

Quando não há a distribuição uniforme das estações pluviométricas dentro da bacia, indica-se que sejam utilizados outros métodos para cálculo da precipitação média, como o método dos polígonos de Thiessen, utilizado nesse estudo (Figura 2, Tabelas 5, 6 e 7).

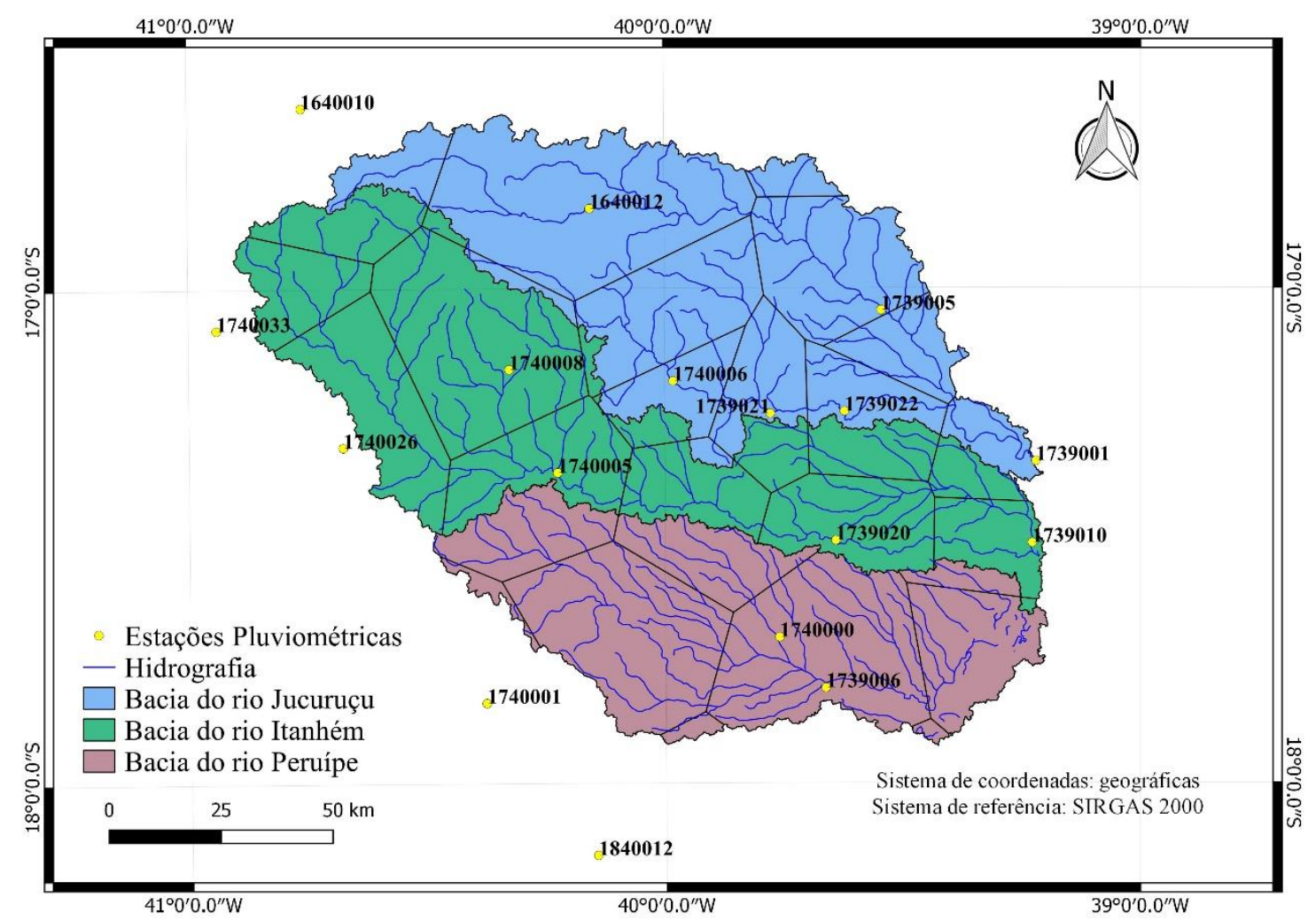

Figura 2: Polígonos de Thiessen para as bacias dos rios Peruípe, Itanhém e Jucuruçu, Bahia. Fonte:[22];Elaborada pelos autores

Tabela 5: Contribuição da precipitação de cada estação pluviométrica para a bacia do rio Itanhém, Bahia.

\begin{tabular}{llcccc}
\hline Código & Município & Área $\left(\mathbf{k m}^{2}\right)$ & Área na Bacia $(\%)$ & Total Anual (mm) & Contribuição $(\mathbf{m m})$ \\
\hline 01640010 & Felisburgo & 356,38 & $6 \%$ & $876,32 \pm 214,19$ & 49,10 \\
01740005 & Medeiros Neto & 817,03 & $13 \%$ & $920,18 \pm 284,26$ & 118,21 \\
01739010 & Alcobaça & 379,32 & $6 \%$ & $1.381,98 \pm 506,17$ & 82,42 \\
01739020 & Teixeira de Freitas & 737,68 & $12 \%$ & $1.063,26 \pm 385,06$ & 123,32 \\
01740026 & Umburatiba & 792,12 & $12 \%$ & $940,20 \pm 306,13$ & 117,10 \\
01739021 & Prado & 378,25 & $6 \%$ & $1.077,29 \pm 368,72$ & 64,07 \\
01739022 & Prado & 341,59 & $5 \%$ & $1.018,32 \pm 342,45$ & 54,69 \\
01739001 & Prado & 185,55 & $3 \%$ & $1.148,92 \pm 447,98$ & 33,52 \\
01740008 & Itanhém & $1.511,97$ & $24 \%$ & $1.094,57 \pm 246,04$ & 260,21 \\
01740006 & Vereda & 268,24 & $4 \%$ & $1.024,28 \pm 362,34$ & 43,20 \\
01740033 & Águas Formosas & 565,84 & $9 \%$ & $1.108,65 \pm 248,24$ & 98,63 \\
01640012 & Itamaraju & 26,10 & $0 \% *$ & $1.009,18 \pm 265,78$ & 4,14 \\
\hline TOTAL & & $6.360,07$ & $100 \%$ & $1.055,26 \pm 130,88$ & $1.048,62$ \\
\hline
\end{tabular}

*Área de influência menor que $1 \%$. Fonte: os autores. 
Tabela 6: Contribuição da precipitação de cada estação pluviométrica para a bacia do rio Jucuruçu, Bahia.

\begin{tabular}{llcccc}
\hline Código & Município & Área $\left(\mathbf{k m}^{2}\right)$ & Área na Bacia $(\%)$ & Total Anual (mm) & Contribuição (mm) \\
\hline 01740005 & Medeiros Neto & 0,69 & $0 \%^{*}$ & $920,18 \pm 284,26$ & 0,11 \\
01739021 & Prado & 493,04 & $8 \%$ & $1.077,29 \pm 368,72$ & 89,20 \\
01739022 & Prado & 409,75 & $7 \%$ & $1.018,32 \pm 342,45$ & 70,07 \\
01739001 & Prado & 223,54 & $4 \%$ & $1.148,92 \pm 447,98$ & 43,13 \\
01740008 & Itanhém & 105,10 & $2 \%$ & $1.094,57 \pm 246,04$ & 19,32 \\
01740006 & Vereda & $1.033,70$ & $17 \%$ & $1.024,28 \pm 362,34$ & 177,80 \\
01739005 & Itamaraju & $1.403,74$ & $24 \%$ & $1.257,96 \pm 379,29$ & 296,54 \\
01640012 & Itamaraju & $2.023,21$ & $34 \%$ & $1.009,18 \pm 265,78$ & 342,88 \\
01640010 & Felisburgo & 260,80 & $4 \%$ & $876,32 \pm 214,19$ & 38,38 \\
01640009 & Rubim & 1,24 & $0 \% *$ & $796,56 \pm 269,63$ & 0,17 \\
\hline TOTAL & & $5.954,81$ & $100 \%$ & $1.022,36 \pm 318,07$ & $1.077,59$ \\
\hline
\end{tabular}

*Área de influência menor que $1 \%$. Fonte: os autores.

Tabela 7: Contribuição da precipitação de cada estação pluviométrica para a bacia do rio Peruípe, Bahia.

\begin{tabular}{llcccc}
\hline Código & Município & Área $\left(\mathbf{k m}^{2}\right)$ & Área na Bacia $(\%)$ & Total Anual $(\mathbf{m m})$ & Contribuição $(\mathbf{m m})$ \\
\hline 01739020 & Teixeira de Freitas & 754,11 & $16 \%$ & $1.063,26 \pm 385,06$ & 171,79 \\
01739006 & Nova Viçosa & $1.696,59$ & $36 \%$ & $1.324,13 \pm 299,49$ & 481,33 \\
01840012 & Montanha & 99,97 & $2 \%$ & $1.013,71 \pm 333,11$ & 21,71 \\
01740001 & Nanuque & 520,34 & $11 \%$ & $890,89 \pm 302,92$ & 99,32 \\
01739010 & Alcobaça & 491,80 & $11 \%$ & $1.381,98 \pm 506,17$ & 145,62 \\
01740005 & Medeiros Neto & $1.081,04$ & $23 \%$ & $920,18 \pm 284,26$ & 213,13 \\
01740026 & Umburatiba & 7,65 & $0 \%$ & $940,20 \pm 306,13$ & 1,54 \\
01739021 & Prado & 15,29 & $0 \%$ & $1.077,29 \pm 368,72$ & 3,53 \\
01740006 & Vereda & 0,47 & $0 \%$ & $1.024,28 \pm 362,34$ & 0,10 \\
\hline TOTAL & & $4.667,27$ & $100 \%$ & $1.070,66 \pm 349,80$ & $1.138,09$ \\
\hline
\end{tabular}

*Área de influência menor que $1 \%$. Fonte: os autores.

Entre as bacias estudadas, a bacia hidrográfica do rio Peruípe apresentou a maior precipitação média pelos polígonos de Thiessen. Esse fato pode ser melhor compreendido através da análise da distribuição espacial de suas estações: as que exercem maior influência na precipitação estão localizadas na faixa litorânea e as com menor área de influência se localizam mais a oeste. O oposto ocorre com a distribuição espacial das estações da bacia do rio Itanhém, que apresentou o menor índice de precipitação média. Outro fato que justifica a maior precipitação na bacia do rio Peruípe é o de que a umidade principal para a formação da precipitação é oriunda do Oceano, assim, a bacia do rio Peruípe está com sua área, proporcionalmente, mais próxima do oceano Atlântico.

O cálculo da precipitação média em bacias hidrográficas é frequentemente utilizado em estudos de escoamentos superficiais e subterrâneos, evaporação e infiltração, sendo imprescindível que as estimativas desses valores estejam o mais próximo possível da realidade [30]. De acordo com Marciano et al. (2018) [30], é difícil obter o valor exato de chuva para toda a bacia hidrográfica, pois envolve diversas variáveis de tempo e espaço, no entanto, é um valor indispensável para os estudos hidrológicos. Contudo, é necessário destacar que, no presente estudo, não foi levada em 
consideração a variabilidade sazonal das precipitações calculadas, sendo esse um elemento de grande importância para a caracterização dos regimes pluviométricos de bacias hidrográficas.

\subsection{ANÁLISE DA PRODUTIVIDADE HÍDRICA}

As hipóteses de igualdade de média foram rejeitadas para as estações pluviométricas: Rubim, Fazenda Cascata, Cachoeira Grande, São José do Prado, Morro D'anta, Conceição da Barra e Fazenda Limoeiro (Tabela 8) e para as estações fluviométricas: Jucuruçu e Medeiros Neto para vazões médias; Jucuruçu e São José do Prado para as vazões máximas; e Jucuruçu, São José do Prado, Fazenda Rio do Sul, Fazenda Cascata e Helvécia para as mínimas (Tabelas 9, 10 e 11).

Tabela 8: Análise de estacionariedade das estações pluviométricas das bacias dos rios Peruípe, Itanhém e Jucuruçu, Bahia.

\begin{tabular}{|c|c|c|c|c|c|c|c|}
\hline Estação & Período & $\mathrm{s}^{2}(\mathrm{~A})$ & $\mathrm{s}^{2}(\mathbf{B})$ & Média A & Média B & $\mathbf{T}$ & $\mathbf{F}$ \\
\hline 01640000 & 1948 a 1984 com 1985 a 2019 & $79.613,23$ & $66.246,37$ & 846,52 & 743,94 & 0,11161 & 0,29479 \\
\hline 01640009 & 1995 a 2007 com 2008 a 2019 & $40.735,41$ & $29.294,94$ & 909,38 & 624,73 & $0,00090 *$ & 0,29621 \\
\hline 01640010 & 1995 a 2007 com 2008 a 2019 & $78.817,80$ & $51.019,50$ & 877,63 & 816,20 & 0,55119 & 0,23968 \\
\hline 01640012 & 1992 a 2005 com 2006 a 2019 & $102.557,35$ & $63.593,62$ & $1.037,93$ & 908,34 & 0,38781 & 0,20010 \\
\hline 01641002 & 1941 a 1982 com 1983 a 2019 & $58.572,17$ & $58.075,44$ & 877,03 & 862,62 & 1,99346 & 0,48988 \\
\hline 01739001 & 1958 a 1988 com 1989 a 2019 & $196.389,74$ & $211.559,86$ & $1.205,04$ & $1.214,65$ & 0,93350 & 0,41994 \\
\hline 01739005 & 1954 a 1985 com 1986 a 2019 & $147.689,82$ & $91.658,21$ & $1.317,87$ & $1.233,13$ & 0,33117 & 0,09488 \\
\hline 01739006 & 1942 a 1980 com 1981 a 2019 & $76.913,31$ & $137.157,75$ & $1.396,05$ & $1.275,86$ & 0,11226 & 0,03998 \\
\hline 01739010 & 1953 a 1986 com 1987 a 2019 & $233.101,73$ & $265.981,91$ & $1.447,29$ & $1.368,49$ & 0,52113 & 0,35383 \\
\hline 01739020 & 1994 a 2006 com 2007 a 2019 & $156.247,60$ & $80.257,50$ & $1.296,51$ & 950,78 & $0,01773 *$ & 0,13132 \\
\hline 01739021 & 1993 a 2005 com 2006 a 2018 & $72.576,22$ & $61.452,24$ & 991,82 & $1.266,42$ & $0,01238 *$ & 0,38894 \\
\hline 01739022 & 1993 a 2006 com 2007 a 2019 & $148.229,05$ & $111.457,97$ & $1.026,92$ & $1.053,75$ & 0,84791 & 0,31410 \\
\hline 01740000 & 1945 a 1981 com 1982 a 2019 & $91.038,45$ & $111.638,48$ & 984,14 & 959,95 & 0,74470 & 0,27186 \\
\hline 01740001 & 1943 a 1981 com 1982 a 2019 & $79.028,12$ & $72.572,50$ & 960,30 & 876,70 & 0,19571 & 0,39981 \\
\hline 01740005 & 1953 a 1985 com 1986 a 2019 & $107.910,21$ & $63.694,67$ & 951,08 & 895,21 & 0,44147 & 0,07062 \\
\hline 01740006 & 1955 a 1986 com 1987 a 2019 & $189.861,19$ & $60.880,59$ & 958,53 & $1.126,95$ & $0,03198 *$ & 0,00124 \\
\hline 01740008 & 1966 a 1993 com 1994 a 2019 & $54.610,19$ & $61.421,40$ & $1.149,23$ & $1.048,54$ & 0,15714 & 0,35617 \\
\hline 01740026 & 1977 a 1999 com 2000 a 2019 & $85.021,18$ & $87.294,88$ & 976,73 & 982,65 & 0,94894 & 0,47551 \\
\hline 01740033 & 1995 a 2007 com 2008 a 2019 & $105.201,27$ & $98.735,31$ & $1.158,44$ & 999,38 & 0,22563 & 0,46159 \\
\hline 01839000 & 1951 a 1987 com 1988 a 2019 & $87.699,89$ & $162.931,80$ & $1.160,30$ & 915,03 & $0,00821 *$ & 0,04572 \\
\hline 01839001 & 1931 a 1974 com 1975 a 2019 & $79.672,95$ & $184.296,82$ & $1.360,40$ & $1.148,13$ & $0,00768 *$ & 0,00352 \\
\hline 01840012 & 1970 a 1994 com 1995 a 2019 & $93.742,87$ & $95.278,16$ & $1.140,67$ & 957,08 & $0,04422 *$ & 0,48463 \\
\hline
\end{tabular}

Em que: $\mathrm{s}^{2}$ - variância; * - médias estatisticamente diferentes. Fonte: os autores.

Tabela 9: Estacionariedade das vazões médias das estações fluviométricas das bacias dos rios Peruípe, Itanhém e Jucuruçu, Bahia.

\begin{tabular}{cccccccc}
\hline Estação & Período & $\mathbf{s}^{\mathbf{2}}(\mathbf{A})$ & $\mathbf{s}^{\mathbf{2}} \mathbf{( B )}$ & Média A & Média B & T & F \\
\hline 55330000 & De 1981 a 1997 com 1998 a 2014 & 59,84 & 32,71 & 7,55 & 5,52 & $0,036665 *$ & $0,037180^{*}$ \\
55340000 & De 1954 a 1983 com 1984 a 2014 & 787,09 & 735,95 & 26,95 & 25,01 & 0,685312 & 0,211890 \\
55360000 & De 1954 a 1983 com 1984 a 2013 & $11.640,31$ & $6.163,76$ & 100,99 & 74,48 & 0,447491 & $0,000909 *$ \\
55370000 & De 1965 a 1989 com 1990 a 2014 & 457,82 & 429,00 & 18,04 & 18,84 & 0,615413 & 0,067298 \\
55380000 & De 1968 a 1991 com 1992 a 2014 & 816,86 & 612,18 & 26,87 & 23,25 & 0,400197 & 0,120700 \\
55460000 & De 1953 a 1983 com 1984 a 2014 & 402,51 & 549,22 & 18,69 & 22,80 & 0,050630 & 0,198179 \\
55490000 & De 1966 a 1990 com 1991 a 2014 & $4.505,92$ & $1.999,83$ & 63,90 & 38,81 & $0,001730 *$ & 0,384007 \\
55510000 & De 1963 a 1987 com 1988 a 2014 & 459,38 & 284,60 & 18,59 & 14,70 & 0,267455 & 0,077145 \\
\hline
\end{tabular}


Em que: $\mathrm{s}^{2}$ - variância; * - médias estatisticamente diferentes. Fonte: os autores

Tabela 10: Estacionariedade das vazões máximas das estações fluviométricas das bacias dos rios Peruípe, Itanhém e Jucuruçu, Bahia.

\begin{tabular}{cccccccc}
\hline Estação & Período & $\mathbf{s}^{\mathbf{2}(\mathbf{A})}$ & $\mathbf{s}^{\mathbf{2}}(\mathbf{B})$ & Média A & Média B & $\mathbf{T}$ & $\mathbf{F}$ \\
\hline 55330000 & De 1982 a 1997 com 1998 a 2013 & $2.224,56$ & $1.791,12$ & 45,61 & 39,49 & $0,000000^{*}$ & 0,435396 \\
55340000 & De 1954 a 1983 com 1983 a 2013 & $20.324,38$ & $11.638,32$ & 121,26 & 100,85 & 0,189898 & $0,001009^{*}$ \\
55360000 & De 1954 a 1983 com 1984 a 2013 & $11.640,31$ & $6.163,76$ & 100,99 & 74,48 & $0,021510^{*}$ & $0,017915^{*}$ \\
55370000 & De 1965 a 1989 com 1990 a 2013 & $14.421,21$ & $20.009,98$ & 108,85 & 128,33 & 0,290002 & 0,223560 \\
55380000 & De 1968 a 1990 com 1991 a 2013 & $18.242,96$ & $19.788,15$ & 125,91 & 130,89 & 0,769640 & 0,420298 \\
55460000 & De 1953 a 1983 com 1984 a 2014 & $58.931,14$ & $54.049,00$ & 178,97 & 200,91 & 0,620423 & 0,085828 \\
55490000 & De 1966 a 1989 com 1990 a 2013 & $273.076,51$ & $259.534,83$ & 468,25 & 424,91 & 0,601235 & 0,225894 \\
55510000 & De 1964 a 1988 com 1989 a 2013 & $9.360,22$ & $4.165,33$ & 79,99 & 58,77 & 0,149187 & $0,001244 *$ \\
\hline
\end{tabular}

Em que: $\mathrm{s}^{2}$ - variância; * - médias estatisticamente diferentes. Fonte: os autores.

Tabela 11: Estacionariedade das vazões mínimas das estações fluviométricas das bacias dos rios Peruípe, Itanhém e Jucuruçu, Bahia.

\begin{tabular}{cccccccc}
\hline Estação & Período & $\mathbf{s}^{\mathbf{2}}(\mathbf{A})$ & $\mathbf{s}^{\mathbf{2}}(\mathbf{B})$ & Média A & Média B & $\mathbf{T}$ & $\mathbf{F}$ \\
\hline 55330000 & De 1981 a 1998 com 1998 a 2014 & 7,66 & 4,05 & 2,71 & 1,95 & $0,041606^{*}$ & 0,148428 \\
55340000 & De 1954 a 1984 com 1984 a 2014 & 130,03 & 115,62 & 10,07 & 9,23 & 0,606561 & 0,384884 \\
55360000 & De 1954 a 1984 com 1985 a 2014 & 33,46 & 25,54 & 5,80 & 4,93 & $0,012647^{*}$ & 0,187608 \\
55370000 & De 1966 a 1990 com 1991 a 2014 & 52,77 & 43,90 & 6,77 & 6,19 & 0,217236 & 0,499523 \\
55380000 & De 1968 a 1991 com 1992 a 2014 & 161,01 & 97,86 & 12,17 & 9,44 & $0,008979^{*}$ & 0,067494 \\
55460000 & De 1954 a 1984 com 1986 a 2014 & 75,34 & 83,31 & 8,19 & 8,74 & 0,496619 & 0,448053 \\
55490000 & De 1967 a 1989 com 1990 a 2014 & 428,82 & 125,53 & 20,18 & 8,98 & $0,000001^{*}$ & 0,296934 \\
55510000 & De 1963 a 1989 com 1989 a 2014 & 114,71 & 60,77 & 10,02 & 7,30 & $0,045373^{*}$ & 0,071165 \\
\hline
\end{tabular}

Em que: $\mathrm{s}^{2}$ - variância; * - médias estatisticamente diferentes. Fonte: os autores.

A rejeição da hipótese de nulidade pode significar uma tendência da redução desses parâmetros ao longo do tempo, uma vez que no primeiro período de estudo foram observados valores médios superiores aos observados no período seguinte. A redução dos totais precipitados reflete diretamente nas vazões mínimas, considerando que $63 \%$ das estações fluviométricas apresentaram tendência de diminuição dessas vazões ao longo do tempo. A vazão mínima permite caracterizar a disponibilidade hídrica natural de um curso de água e pode ser considerada um dos limitantes para concessão de outorga de direito de uso dos recursos hídricos [31]. A sua diminuição pode resultar em déficit hídrico nessas bacias, ponderando que esse é o nível de vazão que assegura a qualidade e quantidade de água necessária para manter minimamente os componentes, funções e processos dos ecossistemas aquáticos.

A diminuição das áreas de vegetação nativa em virtude do crescimento de áreas de monocultura causa influência na quantidade e na qualidade de água disponível em uma bacia. Áreas dominadas pela pecuária, como é o caso da região em que estão inseridas as bacias hidrográficas estudadas onde essa atividade é responsável por 36\% de ocupação da área total do território [32] - apresentam solos compactados que geram uma menor taxa de infiltração e tempo de residência da água [33], portanto, uma menor produtividade hídrica. Corroborando com essa hipótese, Calijuri et al. (2015) [34] constataram que, o aumento significativo de usos antrópicos do solo na bacia hidrográfica do Alto Paraguaçu, acarretou uma variação na precipitação que, consequentemente influenciou na disponibilidade hídrica dessa bacia. Da mesma maneira, Santos et al. (2010) [35] verificaram que a expansão da agricultura em virtude de áreas de vegetação nativa, na bacia hidrográfica do ribeirão 
João Leite em Goiânia, foram fatores preponderantes para a alteração do regime hídrico da bacia, principalmente em função do aumento expressivo do volume de água captado dos mananciais.

A compactação do solo, além de influenciar diretamente as vazões mínimas, influencia também as vazões máximas, ao aumentar o escoamento superficial, demonstrando que o cálculo de vazões é relevante para a previsão e controle de enchentes. Considerando que a estação de Teixeira de Freitas - BA (55490000) apresentou a maior vazão máxima (Tabela 12), é possível que os efeitos de uma cheia pudessem ser mais prejudiciais para a bacia do rio Itanhém do que para as demais bacias estudadas. Porém, são necessários estudos sobre a fisiografia dessas bacias a fim de proceder uma comparação mais contundente.

Tabela 12: Vazões máxima, mínima, média e de referência das estações fluviométricas das bacias hidrográficas dos rios Peruípe, Itanhém e Jucuruçu, Bahia, em $\mathrm{m}^{3} \mathrm{~s}^{-1}$

\begin{tabular}{ccccccccc}
\hline & ITA $^{\mathbf{1}}$ & JUC $^{\mathbf{1}}$ & SJP $^{\mathbf{1}}$ & $\mathbf{C A G}^{\mathbf{1}}$ & FRS $^{\mathbf{1}}$ & MEN $^{\mathbf{2}}$ & FAC $^{\mathbf{2}}$ & HEL $^{\mathbf{3}}$ \\
\hline $\mathbf{Q}_{\mathbf{m a x}}$ & 107,02 & 40,07 & 81,81 & 254,45 & 122,75 & 183,72 & 427,97 & 65,90 \\
$\mathbf{Q}_{\text {min }}$ & 9,33 & 2,20 & 5,09 & 6,33 & 10,29 & 8,20 & 13,97 & 8,23 \\
$\mathbf{Q}_{\text {med }}$ & 25,53 & 6,33 & 11,29 & 18,06 & 24,55 & 19,64 & 49,52 & 15,93 \\
$\mathbf{Q}_{7}$ & 11,78 & 1,96 & 4,50 & 6,49 & 8,33 & 5,25 & 8,60 & 6,99 \\
$\mathbf{Q}_{\mathbf{5 0}}$ & 21,03 & 4,59 & 9,26 & 1,32 & 1,89 & 1,53 & 2,87 & 1,46 \\
$\mathbf{Q}_{90}$ & 8,36 & 2,39 & 5,19 & 6,19 & 9,95 & 8,09 & 9,00 & 6,07 \\
$\mathbf{Q}_{\mathbf{9 5}}$ & 5,64 & 1,90 & 4,48 & 4,77 & 8,34 & 6,81 & 4,78 & 5,15 \\
\hline
\end{tabular}

Em que: ITA - Itamaraju; JUC - Jucuruçu; SJP - São José do Prado; CAG - Cachoeira Grande; FRS Fazenda Rio do Sul; MEN - Medeiros Neto; FAC - Fazenda Cascata; HEL - Helvécia; 1 - Bacia Jucuruçu; 2 - Bacia Itanhém; 3 - Bacia Peruípe. Fonte: os autores.

Essas informações hidrológicas são fundamentais para subsidiar o manejo das bacias hidrográficas no que diz respeito aos aspectos de drenagem superficial [36], controle de inundações e dimensionamento de obras hidráulicas. Levando em consideração as vazões médias específicas de cada estação (Tabela 13), é possível dizer que a bacia hidrográfica do rio Jucuruçu possui uma maior produtividade hídrica quando comparada às outras duas bacias por ter apresentado os maiores valores para a vazão mínima e vazões de permanência específicas. Tais vazões, permitem caracterizar a disponibilidade hídrica na área de drenagem de cada estação fluviométrica.

Tabela 13: Vazões específicas máxima, mínima e média das estações fluviométricas das bacias hidrográficas dos rios Peruípe, Itanhém e Jucuruçu, Bahia, em $\mathrm{m}^{3} \mathrm{~s}^{-1} \mathrm{~km}^{2}$

\begin{tabular}{ccccccccc}
\hline & ITA $^{\mathbf{1}}$ & JUC $^{\mathbf{1}}$ & $\mathbf{S J P}^{\mathbf{1}}$ & $\mathbf{C A G}^{\mathbf{1}}$ & $\mathbf{F R S}^{\mathbf{1}}$ & $\mathbf{M E N}^{\mathbf{2}}$ & FAC $^{\mathbf{2}}$ & HEL $^{\mathbf{3}}$ \\
\hline $\mathbf{q}_{\mathbf{m a x}}$ & 0,038774 & 0,042807 & 0,093179 & 0,141361 & 0,061993 & 0,056879 & 0,090672 & 0,022265 \\
$\mathbf{q}_{\text {min }}$ & 0,00338 & 0,002352 & 0,005801 & 0,003519 & 0,005199 & 0,002539 & 0,00296 & 0,002779 \\
$\mathbf{q}_{\text {med }}$ & 0,00925 & 0,006766 & 0,012856 & 0,010035 & 0,012401 & 0,00608 & 0,010491 & 0,005382 \\
$\mathbf{q}_{7}$ & 0,007621 & 0,004902 & 0,010547 & 0,000733 & 0,000955 & 0,000474 & 0,000608 & 0,000493 \\
$\mathbf{q 5 0}_{\mathbf{1 5 0}}$ & 0,004418 & 0,003160 & 0,007153 & 0,004428 & 0,000616 & 0,000313 & 0,00032 & 0,002588 \\
$\mathbf{q 9 0}$ & 0,003027 & 0,002550 & 0,005911 & 0,003439 & 0,005025 & 0,002505 & 0,001907 & 0,002051 \\
$\mathbf{q 9 5}$ & 0,002045 & 0,002030 & 0,005103 & 0,002650 & 0,004212 & 0,002108 & 0,001013 & 0,001740 \\
\hline
\end{tabular}

Em que: ITA - Itamaraju; JUC - Jucuruçu; SJP - São José do Prado; CAG - Cachoeira Grande; FRS Fazenda Rio do Sul; MEN - Medeiros Neto; FAC - Fazenda Cascata; HEL - Helvécia; 1 - Bacia Jucuruçu; 2 - Bacia Itanhém; 3 - Bacia Peruípe. Fonte: os autores.

\subsection{OUTORGA DOS RECURSOS HÍDRICOS}

Das três bacias hidrográficas estudadas, duas são de domínio da união: bacia hidrográfica do rio Itanhém e bacia hidrográfica do rio Jucuruçu, por pertencerem a mais de um estado (Bahia e Minas Gerais); e a bacia hidrográfica do rio Peruípe é de domínio estatal, por se localizar inteiramente no estado da Bahia. Para rios da união, o limite de outorga é de $70 \%$ da $Q_{95}$, podendo variar em função 
das peculiaridades de cada região [37]. Na Bahia, o Decreto n. 6.296 de 21 de março de 1997 [26], prevê como limite de outorga $80 \%$ da $\mathrm{Q}_{90}$, podendo chegar a $95 \%$ em casos de abastecimento humano. Em Minas Gerais, a Portaria n. 49 de 01 de julho de 2010 [38], fixa em 30\% da $\mathrm{Q}_{7,10} \mathrm{O}$ limite outorgável para captações e em reservatórios. Essa portaria faz uma ressalva para a possibilidade de serem liberadas vazões superiores, mantendo o mínimo residual de $70 \%$ da $\mathrm{Q}_{7,10}$ durante todo o tempo. Com base nas análises e legislação vigente, apresenta-se na Tabela 14 as vazões outorgáveis para cada estação analisada. Todos os valores passíveis de outorga referem-se apenas às estações mencionadas, tornando necessária a regionalização hidrológica para o conhecimento dos valores outorgáveis nos demais pontos das bacias.

Tabela 14: Vazões de referência para fins de outorga correspondentes às estações pertencentes as bacias dos rios Peruípe, Itanhém e Jucuruçu, Bahia, em $\mathrm{m}^{3} \mathrm{~s}^{-1}$

\begin{tabular}{ccccc}
\hline Código & Nome & Município & $\begin{array}{c}\text { Bacia } \\
\text { Hidrográfica }\end{array}$ & $\begin{array}{c}\text { Vazões de } \\
\text { referência* }\end{array}$ \\
\hline 55340000 & Itamaraju & Itamaraju & Jucuruçu & 3,95 \\
55360000 & São José do Prado & Nazaré & Jucuruçu & 3,14 \\
55370000 & Cachoeira Grande & Prado & Jucuruçu & 3,34 \\
55380000 & Fazenda Rio do Sul & Prado & Jucuruçu & 5,84 \\
55460000 & Medeiros Neto & Medeiros Neto & Itanhém & 4,77 \\
55490000 & Fazenda Cascata & Teixeira de Freitas & Itanhém & 3,35 \\
55510000 & Helvécia & Nova Viçosa & Peruípe & 4,86 \\
55330000 & Jucuruçu & Jucuruçu & Jucuruçu & 1,33 \\
\hline
\end{tabular}

* Estações localizadas nas bacias dos rios Jucuruçu e Itanhém: 70\% da Q95: Estação localizada na bacia do rio Peruípe: $80 \%$ da Q95. Fonte: os autores.

A Figura 3 demonstra as atividades de uso da água nas bacias estudadas, tanto em âmbito federal (ANA) quanto em âmbito estadual (INEMA). É perceptível que as atividades desenvolvidas demandam uma alta quantidade de água, fato que é agravado por se tratar de usos consuntivos, que é quando se utiliza a água direto de sua fonte natural e ocorrem perdas na quantidade de água que retorna ao curso hídrico, sendo esses os usos que mais causam escassez desse recurso em âmbito mundial [39].

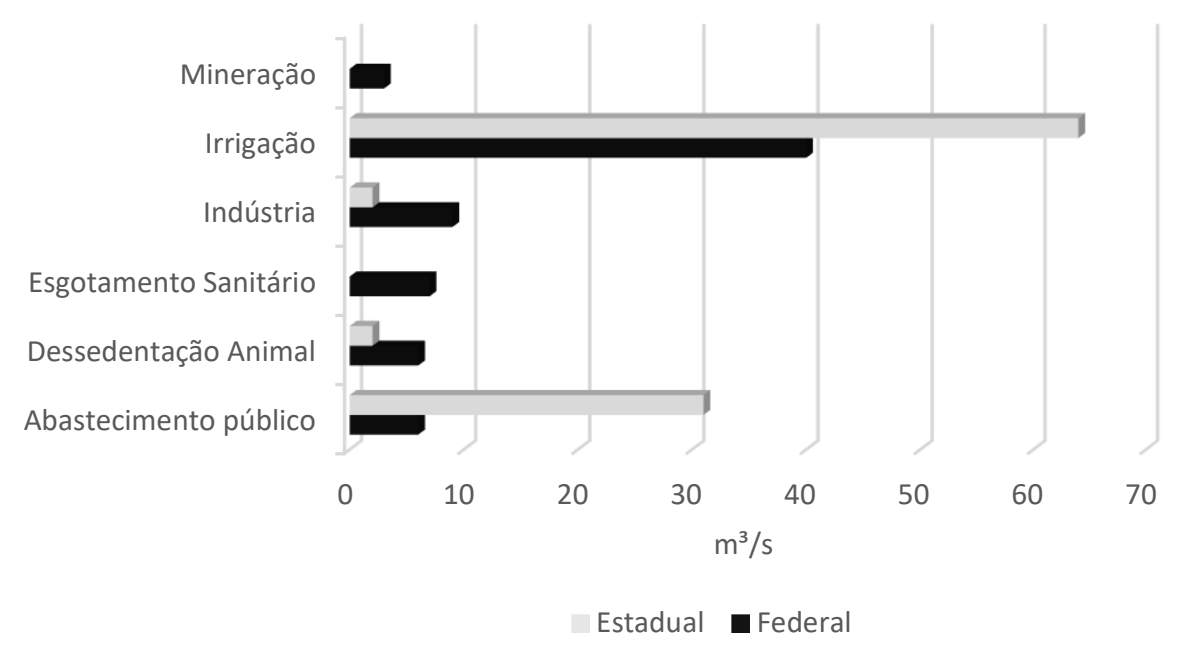

Figura 3: Atividades outorgadas nas bacias dos rios Peruípe, Itanhém e Jucuruçu, Bahia, em âmbito estadual e federal. Fonte: [40,41].

As outorgas concedidas para irrigação representam $61,18 \%$ do total de outorgas concedidas nas bacias estudadas. A irrigação possui um alto consumo dos recursos hídricos em virtude de períodos críticos que a atividade pode sofrer, principalmente, nos locais mais distantes do litoral, que apresentam períodos secos e chuvosos bem definidos. As outras outorgas concedidas representam 
juntas 38,82\% do total de uso da água, sendo: abastecimento público (21,8\%), indústria (6,5\%), dessedentação animal $(4,7 \%)$, esgotamento sanitário $(4,1 \%)$ e mineração $(1,8 \%)$.

Diante do exposto, nota-se que os recursos hídricos das bacias dos rios Peruípe, Itanhém e Jucuruçu precisam ser conservados e geridos de modo a garantir a disponibilidade hídrica para os diversos usos, inclusive para os já outorgados, visto que esses volumes autorizados são significativos quando comparados às vazões de referência calculadas. A grande demanda de múltiplos usos da água, requer planejamentos específicos dos recursos de hídricos, sendo importante que o comitê de gestão dessas bacias, atue criando mecanismos que gerenciem as outorgas concedidas e controle de forma mais acentuada o uso indiscriminado de água, visto que, há fortes indícios de que uma má gestão dos recursos hídricos pode ocasionar crise hídrica na região [42].

\section{CONCLUSÃO}

É possível perceber a influência marítima e continental no regime pluviométrico das bacias estudadas, uma vez que as estações que se localizam mais a oeste dispõem de períodos secos e chuvosos acentuados, enquanto nas estações próximas ao litoral verifica-se menor oscilação nos valores dos totais precipitados durante os períodos do ano. Esse fato é constatado ao analisar a precipitação média das bacias, comprovando que as estações com maior influência se localizam mais próximas à faixa litorânea.

Observou-se que as estações fluviométricas têm apresentado tendência de diminuição de suas vazões, principalmente as vazões mínimas, fato que requer bastante atenção, pois pode resultar em déficit hídrico nessas bacias, considerando que esse é o nível de vazão que assegura a qualidade e quantidade de água necessária para manter minimamente os componentes, funções e processos dos ecossistemas aquáticos. Isso evidencia a necessidade de intervenções que garantam o adequado manejo dessas bacias com intuito de evitar uma crise hídrica na região.

Levando em consideração o fato das vazões específicas representarem a produtividade hídrica em cada área de drenagem das estações fluviométricas, é possível afirmar que a bacia hidrográfica do rio Jucuruçu possui maior produtividade hídrica quando comparada às demais bacias estudadas, visto que as estações fluviométricas presentes nessa bacia apresentaram os maiores valores para as vazões específicas mínimas e de permanência.

\section{AGRADECIMENTOS}

À Fundação de Amparo à Pesquisa do Estado da Bahia, FAPESB.

\section{REFERÊNCIAS BIBLIOGRÁFICAS}

1. Almeida TM, Moreau AMSS, Moreau MS, Pires MM, Fontes EO, Góes LM. Reorganização socioeconômica no extremo sul da Bahia decorrente da introdução da cultura do eucalipto. Soc Nat. 2008 Dez;20(2):5-18, doi: 10.1590/S1982-45132008000200001

2. Almeida TM, Teixeira ACO. Inter-relações entre fatores físicos e socioeconômicos na dinâmica de uso da terra no Extremo Sul da Bahia. Rev Geogr Acad. 2010;4(2):64-72.

3. Malina LL. A territorialização do monopólio no setor celulístico-papeleiro: a atuação da Veracel Celulose no Extremo Sul da Bahia [dissertação]. São Paulo (SP): Universidade de São Paulo; 2013. 358f.

4. Leonel MS. Extremo Sul da Bahia: Caracterização socioeconômica e os impactos da expansão do setor de base florestal [tese]. Belo Horizonte (MG): Universidade Federal de Minas Gerais; 2016. $196 \mathrm{f}$.

5. Perpetua GM, Thomaz Jr A. Revisitando o conceito de acumulação do capital: A pilhagem territorial promovida pela Veracel Celulose no Extremo Sul da Bahia. Campo-Território: Rev Geogr Agr. 2016;11(23):225-256, doi: 10.14393/RCT112308

6. Cerqueira Neto SPG. Construção Geográfica do Extremo Sul da Bahia. RevGeografia. 2013;30(1):246264.

7. Cerqueira Neto SPG, Silva LTO. O que é Extremo Sul da Bahia no século XXI em tempos de globalização. Geografares. 2016;sv(18):23-27, doi: 10.7147/GEO18.8407

8. Martins ML. Ferrovias e desenvolvimento regional em Minas Gerais: o caso da Bahia-Minas. Seculum Rev Hist. 2015;sv(32):69-90.

9. Brasil. Presidência da República. Lei n. ${ }^{\circ}$ 9.433, de 08 de janeiro de 1997. Brasília, DF, 08 de jan. de 1997.

10. Bahia. Decreto CONERH n. 63, de 26 de novembro de 2009. Salvador, BA, n. 20.147, 4 dez 2009. 
11. Rodrigues RDG. Proposta conceitual para a regionalização de vazões [tese]. Viçosa (MG): Universidade Federal de Viçosa; 2008. 195 p.

12. Ribeiro MAFM, Barbosa DL, Batista MLC, Albuquerque JPT, Almeida MA, Ribeiro MMR. Simulação da prioridade de uso das águas superficiais como um critério para o instrumento da outorga. Rev Bras Rec Hídr. 2014;19(2):135-145, doi: 10.21168/rbrh.v19n2.p135-145

13. Calegario AT. Identificação de regiões hidrologicamente homogêneas e comportamento das vazões mínima e média regionalizadas [dissertação]. Viçosa (MG): Universidade Federal de Viçosa; $2014.80 \mathrm{f}$.

14. Snelder TH, Lamouroux N, Leathwick JR, Pella H, Sauquet E, Shankar U. Predictive mapping of the natural flow regimes of France. J Hydrol. 2009;373(1-2):56-67, doi: doi.org/10.1016/j.jhydrol.2009.04.011

15. Berhanu B, Seleshi Y, Demisse SS, Melesse AM. Flow Regime Classification and Hydrological Characterization: A Case Study of Ethiopian Rivers. Water 2015;7(6):3149-3165, doi: 10.3390/w7063149.

16. Scheneider EHM, Barbosa AG, Rocha IML, Mendes LA. Regionalização das vazões de permanência para as bacias hidrográficas do Estado de Sergipe segundo suas regiões climáticas. Sci Plena. 2017;13(10):109901, doi: 10.14808/sci.plena.2017.109901.

17. Santos MO, Barreto IDC, Silva IML, Stosic T. Avaliação das alterações hidrológicas da bacia do rio São Francisco causadas pela construção da usina hidrelétrica de Sobradinho. Sci Plena. 2017;13(11):110202, doi: 10.14808/sci.plena.2017.110202.

18. Ruthes JM. A curva de permanência e a disponibilidade hídrica para outorga no estado do Paraná [dissertação]. Cascavel (PR): Universidade Estadual do Oeste do Paraná; 2017. 62 f.

19. Arai FK, Pereira SB, Gonçalves GGG. Characterization of water availability in a hydrographic basin. Eng Agríc. 2012 Jun;32(3):591-601, doi: 10.1590/S0100-69162012000300018

20. CEMIG - Companhia energética de Minas Gerais [Internet]. Bacia do Leste. Portal da CEMIG [citado em 2020]. Disponível em:< https://bit.ly/2zEsR7Y >. Acesso em 10 jul. 2020.

21. INEMA - Instituto do Meio Ambiente e Recursos Hídricos [Internet]. CBH Peruípe, Itanhém e Jucuruçu [citado em 2020]. Disponível em: < http://www.inema.ba.gov.br/gestao 2/comitesdebacias/comites/cbhperuipe-itanhem-e-jucurucu/jucurucu/>. Acesso em: 10 jul. 2020.

22. ANA - Agência Nacional de Água. Sistema Nacional de Informações Sobre Recursos Hídricos [Internet]. Hidroweb [citado em 2020] Disponível em: <http://hidroweb.ana.gov.br/>. Acesso em: 20 mar. 2020.

23. Sousa HT, Pruski FF, Bof LHN, Cecon PR, Sousa JRC. SisCAH - Sistema Computacional para Análise Hidrológica. Versão 1.0. Grupo de Pesquisa em Recursos Hídricos, 2009.

24. ANA - Agência Nacional de Água. Sistema Nacional de Informações Sobre Recursos Hídricos [Internet]. Software Hidro 1.4 [citado em 2020]. Disponível em: <http://www.snirh.gov.br/portal/snirh/snirh1/sistemas>. Acesso em: 20 mar. 2020.

25. QGIS Development Team, 2019. QGIS Geographic Information System. Open Source Geospatial Foundation Project. Disponível em: <http://www.qgis.org/>. Acesso em: 20 mai. 2019

26. Bahia. Decreto n. 6.296, de 21 de março de 1997. Salvador, BA, 21 de mar. de 1997.

27. Molion LCB, Bernardo SO. Uma revisão da dinâmica das chuvas no nordeste brasileiro. Rev Bras Meteorol. 2002;17(sn):1-10.

28. Cavalcanti IFA, Ferreira NJ, Dias MAF, Justi MGA. Terra e clima no Brasil. São Paulo: Editora Oficina de Textos; 2009. 464 p.

29. Dourado, CS, Stanley RMO, Avila AMH. Análise de zonas homogêneas em séries temporais de precipitação no Estado da Bahia. Bragantia 2013;72(2):102-198, doi: 10.1590/S000687052013000200012

30. Marciano AG, Barbosa AA, Silva APM. Cálculo de precipitação média utilizando método de Thiessen e as linhas de cumeada. Rev Ambiente Água. 2018;13(1):e1906, doi: 10.4136/ambi-agua.1906.

31. Uliana EM, Souza LCS, Silva DD, Souza AP, Almeida FT, Araujo AB. Regionalização de vazões para o médio e alto Rio Teles Pires -MT. Rev Ciên Agr. 2016 Out/Dez;59(4):333-338, doi: 10.4322/rca.2240.

32. BAHIA, 2016. Plano Territorial De Desenvolvimento Sustentável e Solidário do Extremo Sul da Bahia [citado em 2020]. Governo do Estado da Bahia: Secretaria de Planejamento. Disponível em: < encurtador.com.br/qvIT2>. Acesso em: 10 jul. 2020.

33. Almeida AQ. Dinâmica hídrica em microbacias cultivadas com eucalipto e pastagem no leste de Minas Gerais [tese]. Viçosa (MG): Universidade Federal de Viçosa; 2012. 77 f.

34. Calijuri ML, Castro J, Costa LS, et al. Impact of land use/land cover changes on water quality and hydrological behavior of an agricultural subwatershed. Environ Earth Sci 2015;74:373-5382, doi: 10.1007/s12665-015-4550-0

35. Santos EHM, Griebeler NP, Oliveira LFC. Relação entre uso do solo e comportamento hidrológico na Bacia Hidrográfica do Ribeirão João Leite. Rev Bras Eng Agríc Amb. 2010;14(8):826-834, doi: 10.1590/S1415-43662010000800006 
36. Mello CR, Viola MR, Beskow S. Vazões máximas e mínimas para bacias hidrográficas da região alto rio Grande, MG. Ciên Agrotecnol. 2010 Abr;34(2):494-502, doi: 10.1590/S1413-70542010000200031.

37. ANA - Agência Nacional de Água. Outorga de direito de uso de recursos hídricos: cadernos de capacitação em recursos hídricos v. 6, Brasília: ANA; 2011. 50p.

38. IGAM - Instituto Mineiro de Gestão de Águas. Diário do Executivo. Portaria IGAM n ${ }^{\circ} 49$, de 01 de julho de 2010. Minas Gerais, 06 jul. 2010. Seção 3, p. 1-2.

39. ANA - Agência Nacional de Águas. Manual de procedimentos técnicos e administrativos de outorga de direito de uso de recursos hídricos 2013. Agência Nacional de Águas - ANA, Brasília, DF, 2013.

40. ANA - Agência Nacional de Águas. Outorgas Emitidas [ Internet; Citado em 2020]. Disponível em: <https://www.ana.gov.br/regulacao/principais-servicos/outorgas-emitidas>. Acesso em: 20 mar. 2020.

41. INEMA - Instituto do Meio Ambiente e Recursos Hídricos. Novo GeoBahia [Internet]. Módulo do Monitoramento do Sistema Estadual de Informações Ambientais e Recursos Hídricos [citado em 2020]. Disponível em: <http://novogeobahia.inema.ba.gov.br/monitoramento/\#>. Acesso em: 20 mar. 2020.

42. Gomes RRKA, Fernandes LL. Hydrological characterization of the Araguaia River through reference flows. Appl Water Sci. 2017;7:4605-4614, doi: 10.1007/s13201-017-0622-5 